\title{
Preventing drug-related adverse events following hospital discharge: the role of the pharmacist
}

This article was published in the following Dove Press journal:

Integrated Pharmacy Research and Practice

13 February 2017

Number of times this article has been viewed

\author{
Justine Nicholls' \\ Craig MacKenzie \\ Rhiannon Braund ${ }^{2}$ \\ 'Dunedin Hospital Pharmacy, ${ }^{2}$ School \\ of Pharmacy, University of Otago, \\ Dunedin, New Zealand
}

\begin{abstract}
Transition of care (ToC) points, and in particular hospital admission and discharge, can be associated with an increased risk of adverse drug events (ADEs) and other drug-related problems (DRPs). The growing recognition of the pharmacist as an expert in medication management, patient education and communication makes them well placed to intervene. There is evidence to indicate that the inclusion of pharmacists in the health care team at ToC points reduces ADEs and DRPs and improves patient outcomes. The objectives of this paper are to outline the following using current literature: 1) the increased risk of medication-related problems at ToC points; 2) to highlight some strategies that have been successful in reducing these problems; and 3 ) to illustrate how the role of the pharmacist across all facets of care can contribute to the reduction of ADEs, particularly for patients at ToC points.
\end{abstract}

Keywords: pharmacist, adverse drug events, drug-related problems, transitions of care, hospital discharge

\section{Introduction}

In general, the role of the pharmacist, in developed countries, is to deliver a pharmaceutical service to optimize medication therapy in various settings, including pharmaceutical industry, academic research, community pharmacy and hospital pharmacy. ${ }^{1}$ Pharmacists are often the most accessible health care professionals in the community setting and are well placed to offer ongoing medicines management, monitoring, education and advice to their local population to improve medication outcomes and reduce adverse events. ${ }^{1,2}$

The role of the community pharmacist continues to expand in supporting primary care patients, in terms of acute demand management and additional services such as administration of vaccinations and therapeutic drug monitoring, ${ }^{3-7}$ with further expansion evolving into clinical areas and multidisciplinary teams. ${ }^{8}$

The roles of hospital pharmacists also continue to increase in diversity, and by continuing to work as part of the multidisciplinary health care team they can improve medication management within the hospital setting, including medication utilization, clinical review and medication reconciliation (MR) services, ${ }^{9-12}$ provide support and advice in specialist roles such as within antimicrobial stewardship programs, ${ }^{13,14}$ assist in the discharge process by providing patient education to improve health outcomes, ${ }^{15,16}$ improve continuity of care $^{17}$ and prevent adverse drug events (ADEs). ${ }^{15,18}$

An increasing focus on transition of care (ToC) points has been seen, particularly at the point of admission to and discharge from the hospital. This has been driven mostly
Correspondence: Rhiannon Braund Adams Building, 18 Frederick Street, Dunedin 9054, New Zealand

Tel +6434797240

Fax +64 34797034

Email rhiannon.braund@otago.ac.nz 
from the identification of these events as having an increased risk for information transfer to be suboptimal, which can lead to errors and omissions regarding medication therapy. ${ }^{19-21}$ This can result in an increased risk of an ADE, which includes adverse drug reactions (ADRs) or another type of drug-related problem (DRP). Unfortunately, the evidence also shows that many of these ADEs are potentially preventable. ADEs therefore need to be further identified and strategies be employed to reduce the incidence of the preventable ADEs to protect our patients from these adverse outcomes and to ensure that medications are used safely and effectively. ${ }^{22,23}$

This paper specifically focuses on the role of the pharmacist in preventing drug-related adverse events following hospital discharge. The reason for this focus as mentioned earlier is that ToC points are known to be a potential area for ADEs and other DRPs, including errors. Both community and hospital pharmacists can assist with reconciliation of medications, education to patients, communicate changes to other health professionals, and also update and ensure accurate medication-related information in the health record. ${ }^{24}$ This is where pharmacists have an integral role in the prevention of ADEs at discharge.

\section{Medication changes, types of errors and the impact on the health care system}

The Institute of Medicine defines an ADE as "any injury due to medication", and the National Coordination Council for Medication Error Reporting and Prevention (NCCMERP) within the US has produced a document to outline the overlap between similar related terms: http://www.nccmerp.org/sites/ default/files/nccmerp fact sheet 2015-02-v91.pdf

ADEs can be predictable due to the mechanism of action of the drug or the dosage, or can be idiosyncratic. ADEs can have a significant negative impact on patient outcomes and costs to the health care systems. Under the umbrella of ADEs are ADRs. Research shows that up to $30 \%$ of hospital admissions are due to ADRs, and some of these ADRs have potentially severe outcomes, especially in vulnerable populations such as pediatric patients, where up to $39 \%$ of these ADRs can be fatal or life threatening. ${ }^{25}$ ADRs contribute to health care costs by increasing hospital stays, causing readmission to hospital, increased clinical intervention and emergency department (ED) visits. ${ }^{25}$ In the US alone, ADRs cost up to 30.1 billion US dollars per year. ${ }^{25}$ DRPs encompass a much wider group of potential problems that can occur and include ADEs, ADRs and medication errors; ${ }^{26}$ however, the definition and use of DRP classification systems within the literature are not uniform. ${ }^{27}$
It is well documented that during a hospital admission, medication changes occur, ${ }^{15}$ and during the process of these changes, the possibility of medication errors occurs. Rupp et $\mathrm{al}^{28}$ categorized these into several groups but noted particular interest in the difference in errors of commission and errors of omission. Commission is where there is an error that makes it into the documentation (i.e., discharge prescription); although this can be incredibly problematic, a vigilant pharmacist may note an incorrect dose or dosing regimen. However, it is often errors of omission, where a required or recommended medication is omitted that often occur unintentionally. These are harder to determine, and where there are changes to a regular medication regimen it is difficult to determine these errors of omission because it is challenging to determine what the prescriber intended. These errors have a significant dollar and human-associated cost, ${ }^{29}$ and strategies need to be implemented that reduce the occurrence of these discrepancies. ${ }^{30}$

\section{ToC}

Discrepancies with medications can occur throughout the hospital stay and at points of ToC, but they are often more common at admission and discharge..$^{10,11,31}$ One study found that almost half of the patients studied had unexplained discrepancies between preadmission medication regimens and discharge medication orders. ${ }^{15}$ The impact of these discrepancies can contribute to readmission rates; Coleman et $\mathrm{al}^{32}$ found that patients with at least one identified medication discrepancy have a significantly higher rehospitalization rate at 30 days compared to those without identified discrepancies. Patients can be vulnerable to medication errors at transition points, contributed to by a "lack of oversight by health care professionals and an associated lack of accountability". ${ }^{32}$

Successful improvements in the ToC points require consideration of all the following three key components: 1) patient education and health literacy, 2) medication management, and 3) communication processes. Although enhancing medication safety involves the entire health care team and the patient, pharmacist involvement in discharge programs has shown a reduction in readmission rates..$^{15,16,33}$

\section{Prevention of ADEs - admission}

Preventing ADEs postdischarge begins as early as the admission process itself, with hospital admission being a transition point where there is an increased risk of medication errors. ${ }^{10,31}$ Accumulating evidence shows that including a pharmacist in the admission process conducting correct medication history taking and documentation reduces the number of errors that 
occur at this phase of the patient journey and prevents these errors subsequently being propagated through the entire hospital stay and discharge. ${ }^{10,34}$ The role of the pharmacist is not limited to only prescribed medications, but it also includes an accurate history taking of all other medications whether over the counter (OTC) or complementary and includes a full history of previous medication-related adverse events and known drug allergies.

\section{Allergies and adverse drug reactions - documentation}

Patients (and sometimes clinicians) have difficulty differentiating between a true drug allergy and a predictable adverse drug reaction. For example, many patients report mild gastrointestinal disturbance as a drug allergy; however, this may not be a reason to withhold the medication. Poor documentation of adverse drug reactions can lead to suboptimal therapy choice and increased medication expenditure, ${ }^{35-37}$ which is an important area that pharmacists can provide expertise in. One study found that when pharmacists reviewed patient medication charts, the documentation of allergies was more likely to be correct $(13.5 \%$ vs $29.4 \% ; P<0.001) .{ }^{38}$

\section{MR}

MR is the formal process of sourcing and verifying a complete and accurate list of a patient's current medications. ${ }^{24}$ The process is outlined in Figure 1. This includes all prescribed medicines, nonprescription and OTC products. ${ }^{39}$ It is an opportunity to discuss with the patients their adherence, including questioning if they have any swallowing difficulties or issues such as being unable to open containers or remove the tablets from the blisters, and if they are experiencing any adverse effects from their medicines, which may be affecting their adherence. ${ }^{39}$

The determined accurate list of a patient's current medication is then compared with the medications prescribed in the hospital for the patient, to identify and resolve any discrepancies. ${ }^{12}$ Research has shown that for patients in hospital, a quarter of medication errors can be directly attributed to reconciliation of medications taken prior to admission not being completed. ${ }^{11}$ The process of MR "aims to prevent injury by enhancing medication management and providing another layer of safety to the management process". ${ }^{39}$ An unintentional change to regular medications is considered a discrepancy as is an intentional change that has not been documented in the patient medical record. Studies have shown that up to $59 \%$ of these discrepancies will potentially cause an ADE and a third will go on to cause an actual ADE. ${ }^{11}$
Every patient should have their medications reconciled on admission by a pharmacist, but often in the hospital setting, due to the pressure on pharmacy resources, a prioritization system is required to reconcile patients who are considered to be at higher risk for medication errors. ${ }^{11}$

With expert knowledge in medications, the pharmacist is well suited to conduct MR. ${ }^{12,24}$ It has been shown that, when compared with physicians, the pharmacist is more likely to obtain a more complete medication history. ${ }^{10}$ As discrepancies are noted during the process, pharmacists are able to assess and resolve these issues. ${ }^{24}$ Although the recognition of the importance of this role is growing, there are still barriers to MR being adopted and implemented routinely, including resourcing and recognition from other health professionals. ${ }^{40-42}$

A recent meta-analysis on MR programs at hospital transitions involved 19 studies and showed that pharmacyled MR interventions were found to be an effective strategy to reduce medication discrepancies. ${ }^{12}$ It aimed to determine the transition points at which pharmacy involvement is of most benefit and found that when MR was completed at admission or discharge it had more impact than conducting repeated MRs during the multiple transitions within care. ${ }^{12}$

A study conducted in Spain looked at reconciliation discrepancies of patients on admission to an internal medicine department from the ED and on discharge from internal medicine department for those on five or more medications, over a period of 3 years. ${ }^{43}$ They found that almost one-fifth of patients had a discrepancy that required prescriber clarification. The majority of errors were classed as incomplete prescriptions (mostly on discharge), followed by errors of omission and different dosage, frequency or route (both mostly on admission). Of the discrepancies found, most (93\%) of the pharmacist interventions were accepted by the prescriber; those that were not accepted were considered "justified discrepancies" where the intention was to cease a medication or change the dose, route and frequency. ${ }^{43}$

\section{Medicines reconciliation process Patient education}

Pharmacists are well placed to offer patient education on their discharge medications..$^{15,24,39,44}$ This involves providing information on new medications, informing the patients of changes to medication regimens and providing medication summary cards on discharge. At this interaction point, the pharmacist can often identify patients who may be nonadherent and those who need assistance with the financial costs of their prescriptions. The pharmacist can also identify barriers to 


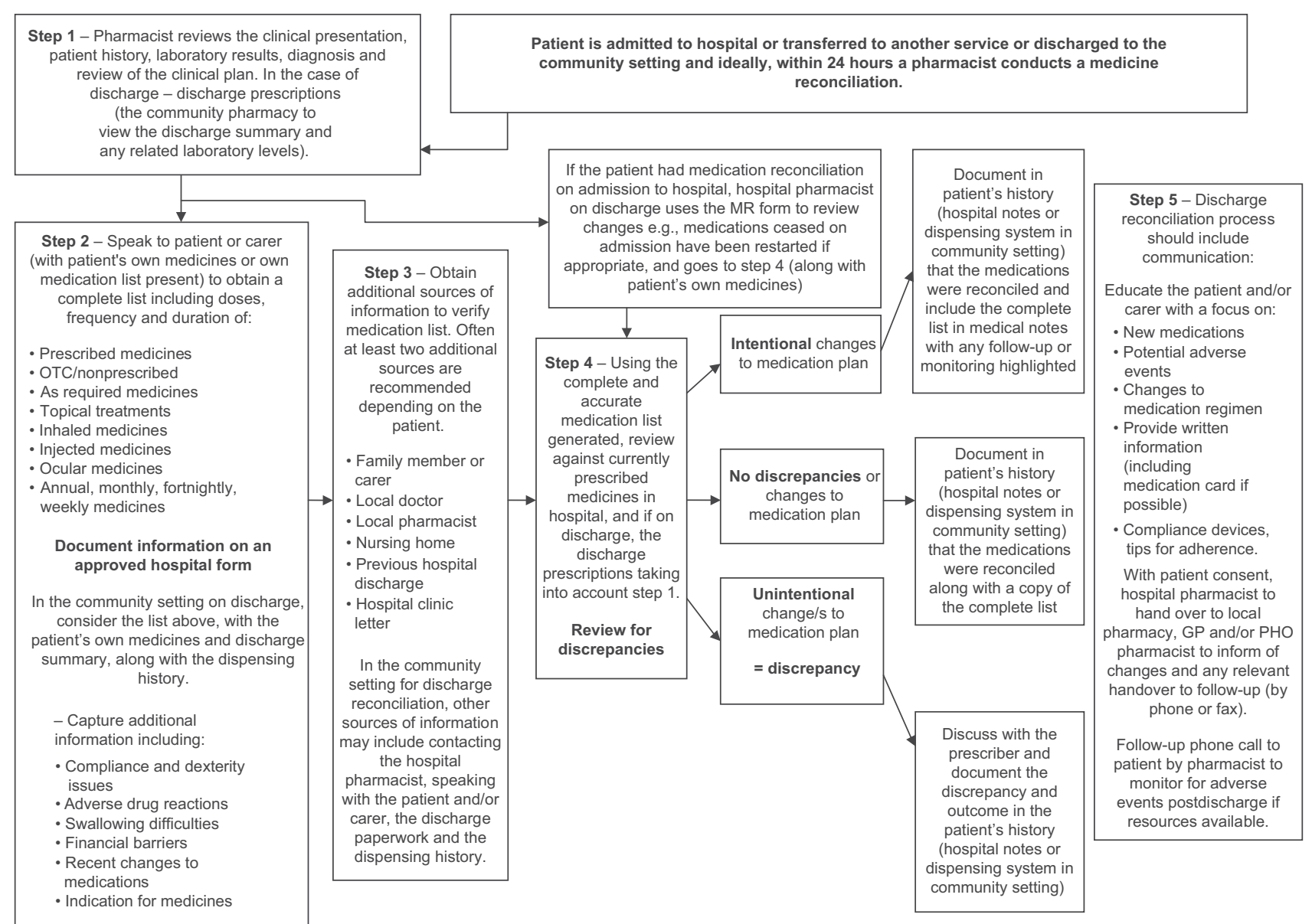

Figure I Schema of the medicines reconciliation process at admission and discharge.

Abbreviations: MR, medication reconciliation; OTC, over the counter; PHO, Primary Health Organization; GP, General Practitioner.

collecting their medications (e.g., inability to drive) and listen to patients' concerns about their medicines and help resolve any issues prior to discharge.

The importance of patient counseling was demonstrated by a randomized controlled study involving medication counseling to elderly patients on discharge. ${ }^{16}$ Study patients were given a copy of the medication and information discharge summary (MIDS), a medication reminder card and education which included why each medication was prescribed, side effects, doses and timing of administration and the importance of compliance. The pharmacist also visited the patients in their homes postdischarge. The study found reduced readmissions to hospital and reduced unplanned visits to the local physician; additionally, the study patients also had increased knowledge of their medications and increased adherence. ${ }^{16}$

A similar study was conducted by Schnipper et $\mathrm{al}^{15}$ where 92 (vs 84 in the control group) patients were provided discharge counseling and a follow-up phone call by the pharmacist. Patients' medications were reconciled, and they were assessed on discharge for previous DRPs and compliance issues. A clinical review was completed of the discharge medications. The phone call included questions on adherence and any adverse effects from medications. The results showed significantly reduced preventable ADEs and reduction in "preventable, medication-related ED visits" and hospital admissions. ${ }^{15}$ Other studies have used similar methods and multiple follow-up phone calls. ${ }^{44}$

\section{Health literacy}

As part of the patient education process, particular attention needs to be given to the health literacy of the patient. There is evidence that patients with low health literacy have poorer health outcomes. ${ }^{45}$ The functional health literacy encompasses a person's ability to read and interpret instructions in terms of a health care setting and has important implications on one's ability to understand medication instructions. ${ }^{46}$ Improving health literacy additionally can improve adherence. ${ }^{47}$ Patients with lower health literacy have less understanding of their medications, and this impacts on their ability to report their medications accurately. ${ }^{48}$ It has been shown that medication 
errors are more common in patients with low numeracy or health literacy. ${ }^{49}$ Communication and education resources must be tailored to the patients' level of health literacy. ${ }^{50}$ It is important to note that there are no standard assessment tools that can be readily used in practice to assist with establishing the level of a patient's health literacy.

\section{Medication management}

Medication management at $\mathrm{ToC}$ points, particularly admission and discharge, should be a primary focus, with the pharmacist able to identify issues with the medication regimen. A medication review and MR should be done to identify and resolve any discrepancies. ${ }^{15}$ This can include a clinical review of current therapies, the potential for adverse effects, any drug interactions and ongoing monitoring requirements. Individualizing doses by ensuring they are appropriate for age, weight, renal function and liver function is a key part of the pharmacist's review.

Other medication management interventions include identifying adherence issues and organizing adherence aids through the community pharmacy, considering alternative formulations for swallowing difficulties and reviewing the timing of medicines to optimize adherence and other issues, ${ }^{51}$ and for those with high clinical needs, a referral to a specialized clinical pharmacist service for ongoing review and follow-up is recommended where these types of services are available.

The development of an MR program that spans the entire patient journey from admission to discharge and that is embedded into the multidisciplinary team, while being pharmacy led, remains a gold standard and will show both patient and health care system benefits. ${ }^{52}$ Having a dedicated pharmacist at the time of discharge has been shown to reduce the number of discrepancies that leave the hospital setting and reach primary care. ${ }^{53} \mathrm{~A}$ specialized ED pharmacist was able to significantly reduce the number of discrepancies on discharge from ED and further the wider team believed that this service improved patient safety and optimized medication regimens. ${ }^{54}$ Project RED "re-engineering discharge" was a program in the US that focused on reducing readmission rates with a thorough discharge package using a nurse to educate, reconcile and arrange follow-up. ${ }^{33} \mathrm{~A}$ follow-up phone call was provided by a clinical pharmacist to review the medications and treatment plan 2-4 days postdischarge. Those patients who received the "Project RED" intervention had a lower hospital utilization rate than those who did not take part. ${ }^{33}$ Other interventions have been implemented, and the majority consist of multiple aspects of MR, patient centered education, follow-up phone calls and visits to patients' homes postdischarge. ${ }^{24}$

\section{Communication}

Effective communication is vital for the handover of essential information regarding changes to medications between health care professionals at care transitions. Over half of all medication errors occur at ToC, especially in the transition from inpatient to outpatient care, and many adverse events can be attributed to ineffective communication from one health care provider to another. ${ }^{24}$ It is estimated that poor communication during ToCs is responsible for roughly one half of all hospital-related medication errors and one-fifth of all ADEs. ${ }^{24}$ Hospital pharmacists have the knowledge, skills and understanding to communicate the patients' clinical plan and updated medication regimen with other health care providers. However, first and foremost, medication-related information needs to be communicated to the patient and family (as discussed in the "Patient education" section).

It is also essential to communicate changes to medications and the discharge plan to relevant health professionals, including the local pharmacy and the local physician. A systematic review on the optimal role of pharmacists in ToC found several effective communication strategies in particular relating to hospital discharges ${ }^{55}$ One of these was a study where pharmacists provided a discharge letter that included changes to medicines and reasons for these, the goals of treatment and the monitoring required. ${ }^{56}$ The same study included a follow-up phone call 2 months postdischarge to the patients to reinforce the interventions made during their hospital stay. ${ }^{56}$ The review emphasized the importance of the pharmacist working closely with the hospital or primary health care team for the best outcomes. ${ }^{55}$

Hospital-based community liaison pharmacists can assist in the transfer of information for secondary to primary care transitions. ${ }^{17}$ A study conducted in Northern Ireland showed that the pharmacist conducted MR, prepared the discharge letter and explained medication changes to the patients during the hospital stay. On discharge, the pharmacist also provided patient counseling and an individualized medication list, a letter for the General Practitioner and local pharmacy with copies of the discharge prescription and an assessment of the patient's own medications prior to discharge. Just over half of the GPs and almost all of the local pharmacies thought that there was an improvement in the standard of discharge information compared to prior to the study. This study also found that the GP and local pharmacy are the best sources of accurate information for compiling a list for reconciliation. ${ }^{17}$ 
One review noted that although studies had indicated that direct verbal communication was preferred by stakeholders, there was a "recommendation for standardization involving written or electronic documentation", as often clinicians are hard to reach when on patient-centered tasks. ${ }^{57}$ Particularly in the community setting, pharmacists often have limited information on the patient, and this can be challenging when the patient has multiple medications, low health literacy and multiple comorbidities. ${ }^{58} \mathrm{~A}$ pilot program in the US demonstrated the effective sharing of vital information on monitoring lab results and treatment plans by allowing the pharmacist to access the electronic health record of a medical center, which resulted in improved communication, trust and professional relationships between pharmacists and the medical center. ${ }^{58}$

\section{Information sharing and the role of the community pharmacist}

An ongoing theme that emerges from the literature regarding medication discrepancies occurring between hospital discharge and returning back to the community is a lack of information transfer and sharing. ${ }^{41,59}$ Although a discharge prescription should provide a complete list of medications that are intended to be continued posthospital discharge, there is a large amount of evidence demonstrating that many errors and discrepancies exist (both errors of omission and commission), ${ }^{60,61}$ which often fall to the community pharmacist to attempt to resolve. ${ }^{62,63}$

Information sharing between the medical practitioners and pharmacists that includes the rationale for medication discontinuation, dosage modification and new treatment initiation should be included in a full discharge summary document and would provide a shared understanding of the patient journey and the therapy goals. ${ }^{58}$ However, in many situations, this full summary is not completed or may only be given to the patient and may take time to be sent to the patient's general practice. Although this summary is not routinely sent to the community pharmacy, the inclusion of the community pharmacy in this information sharing process and the ability to share this information electronically in real time and in a secure fashion is providing more opportunities to enhance communication to all members of the health care team and allow discrepancies to be identified (and resolved) earlier. ${ }^{60}$

There is evidence that including a community pharmacist in the ToC from discharge can reduce DRPs; however, the impact on other outcomes, such as medication adherence and clinical control, is not consistent. ${ }^{64}$ An randomised control trial where a pharmacist case manager was allocated to provide dedicated and specific "enhanced" discharge care to patients showed no statistically significant improvement. ${ }^{65} \mathrm{In}$ this study, the community physician and community pharmacy received a faxed detailed care plan in addition to usual care. The authors believed that this was due to high quality of care measure across both groups. ${ }^{65}$

A successful example of care has been shown in the TransitionRx model ${ }^{66}$ In this study, patients postdischarge were followed up by a community pharmacy based-program that provided a full range of medication management services. The patients who received care from this program had a statistically significant reduction in the 30-day readmission rate. ${ }^{66}$ Ongoing efforts to reach truly seamless care will be strengthened with leadership, tailoring strategies to the local setting and information technology support. ${ }^{19}$

\section{Pharmacists in general practicel primary care}

In some areas, the presence of a clinical pharmacist (or terminology such as Clinical Pharmacist Facilitator, Clinical Advisory Pharmacists, and many others) within a medical practice, either as a permanent appointment or on a visiting basis as a shared resource across multiple practices has been established as a new model for improving appropriate and optimal medicine usage. ${ }^{67}$ Although these roles are primarily established to assist with the management of long-term conditions, provide advice for those with multiple medications, and better access to health checks in primary care, there is a potential referral to these clinical pharmacists for patients with complex medication needs on discharge from hospital.

Although there are multiple ways in which these collaborative care models can be established, ${ }^{68}$ there is already a growing body of literature outlining the benefits (not only to patient care but also to practitioner development and strengthening of interprofessional relationships) and the barriers that exist. ${ }^{69-73}$

\section{Conclusion}

In summary, the role of the pharmacist in preventing ADEs following discharge is one that requires multiple aspects of consideration and centers on three key aspects: 1) patient education and health literacy, 2) medicines management including MR, and 3) communication within the health care team and with patients and their families.

This multifactorial, multidisciplinary, collaborative care approach to medication use needs to be led by pharmacists in their roles as medication managers, communicators and educators. One of the roles that hospital pharmacists need to focus on is MR at admission and discharge (alongside their 
other clinical roles) and communicate with all members of the health care team as medication changes. Hospital pharmacists have a key role to play to ensure any medication changes made are well documented in the patient's medical record. At ToC points, pharmacists have a role in ensuring continuity of information and at the time of discharge can take a lead on the communication and liaising between the secondary/primary interface and work toward a seamless transition approach with general practitioners, community pharmacy and the other primary care providers.

Improving patients' knowledge of their medications and overall health literacy is an important role for all practitioners, but pharmacists are uniquely placed to provide additional support and time. Understanding patients' health beliefs and barriers to medication use is important to improve patient adherence to medication, which in turn will improve patient outcomes. ${ }^{74}$

Shared electronic health records will provide a much more comprehensive and time accessible information source to determine the rationale for individual therapy across all sectors of care during the patient journey.

\section{Disclosure}

The authors report no conflicts of interest in this work.

\section{References}

1. WHO [webpage on the Internet]. Report of a WHO Meeting Tokyo. The Role of the Pharmacist in the Health Care System. Available from: http://apps.who.int/medicinedocs/en/d/Jh2995e/. Accessed January 5, 2017.

2. Chumney EC, Robinson LC. The effects of pharmacist interventions on patients with polypharmacy. Pharm Prac. 2006;4(3):103-109.

3. Bidwell S, Thompson L. GPs, community pharmacists and shifting professional boundaries. N Z Med J. 2015;128(1414):19-26.

4. Ministry of Health. Pharmacy Action Plan 2016 to 2020. Wellington: Ministry of Health; 2016.

5. Nissen L, Campbell C. Be our guest: vaccination status of Australian community pharmacy. Aust Pharm. 2015;34(9):15.

6. Atkins $\mathrm{K}$, van Hoek AJ, Watson C, et al. Seasonal influenza vaccination delivery through community pharmacists in England: evaluation of the London pilot. BMJ Open. 2016;6(2):e009739.

7. Harrison J, Shaw JP, Harrison JE. Anticoagulation management by community pharmacists in New Zealand: an evaluation of a collaborative model in primary care. Int J Pharm Pract. 2015;23(3):173-181.

8. Leutsch K, Rowett D, Punchard H. The sweet spot for pharmacy. J Pharm Pract Res. 2016;46(2):107-111.

9. Kaboli PJ, Hoth AB, McClimon BJ, Schnipper JL. Clinical pharmacists and inpatient medical care: a systematic review. Arch Intern Med. 2006; 166(9):955-964.

10. Steurbaut S, Leemans L, Leysen T, et al. Medication history reconciliation by clinical pharmacists in elderly inpatients admitted from home or a nursing home. Ann Pharmacother. 2010;44(10):1596-1603.

11. Duran-Garcia E, Fernandez-Llamazares CM, Calleja-Hernandez MA. Medication reconciliation: passing phase or real need? Int J Clin Pharm. 2012;34(6):797-802.

12. Mekonnen A, McLachlan A, Brien J. Pharmacy-led medication reconciliation programmes at hospital transitions: a systematic review and meta-analysis. J Clin Pharm Ther. 2016;41(2):128-144.
13. Jamieson C, Woodford Guegan E. Specialist antimicrobial pharmacists. J Infect Prev. 2010;11(4):120-123.

14. Wickens HJ, Farrell S, Ashiru-Oredope DA, et al. The increasing role of pharmacists in antimicrobial stewardship in English hospitals. J Antimicro chemo. 2013;68(11):2675-2681.

15. Schnipper JL, Kirwin JL, Cotugno MC, et al. Role of pharmacist counseling in preventing adverse drug events after hospitalization. Arch Intern Med. 2006;166(5):565-571.

16. Al-Rashed SA, Wright DJ, Roebuck N, Sunter W, Chrystyn H. The value of inpatient pharmaceutical counselling to elderly patients prior to discharge. Br J Clin Pharmacol. 2002;54(6):657-664.

17. Bolas H, Brookes K, Scott M, McElnay J. Evaluation of a hospital-based community liaison pharmacy service in Northern Ireland. Pharm World Sci. 2004;26(2):114-120.

18. Barber N, Smith F, Anderson S. Improving quality of health care: the role of pharmacists. Qual Health Care. 1994;3(3):153-158.

19. Claeys C, Foulon V, de Winter S, Spinewine A. Initiatives promoting seamless care in medication management: an international review of the grey literature. Int J Clin Pharm. 2013;35(6):1040-1052.

20. Haynes KT, Oberne A, Cawthon C, Kripalani S. Pharmacists' recommendations to improve care transitions. Ann Pharmacother. 2012;46(9): $1152-1159$.

21. American College of Clinical Pharmacy, Hume AL, Kirwin J, et al. Improving care transitions: current practice and future opportunities for pharmacists. Pharmacotherapy. 2012;32(11):e326-e337.

22. Al Hamid A, Ghaleb M, Aljadhey H, Aslanpour Z. A systematic review of hospitalization resulting from medicine-related problems in adult patients. Br J Clin Pharmacol. 2014;78(2):202-217.

23. Kongkaew C, Hann M, Mandal J, et al. Risk factors for hospital admissions associated with adverse drug events. Pharmacotherapy. 2013; 33(8):827-837.

24. Johnson A, Guirguis E, Grace Y. Preventing medication errors in transitions of care: a patient case approach. J Am Pharm Assoc. 2015; 55(2):e264-e274.

25. Sultana J, Cutroneo P, Trifiro G. Clinical and economic burden of adverse drug reactions. J Pharmacol Pharmaco. 2013;4(suppl 1):S73-S77.

26. Kaufmann CP, Stampfli D, Hersberger KE, Lampert ML. Determination of risk factors for drug-related problems: a multidisciplinary triangulation process. BMJ Open. 2015;5(3):e006376.

27. Basger BJ, Moles RJ, Chen TF. Application of drug-related problem (DRP) classification systems: a review of the literature. Euro J Clin Pharmacol. 2014;70(7):799-815.

28. Rupp MT, DeYoung M, Schondelmeyer SW. Prescribing problems and pharmacist interventions in community practice. Med Care. 1992; 30(10):926-940.

29. Bates DW, Slight SP. Medication errors: what is their impact? Mayo Clin Proc. 2014;89(8):1027-1029.

30. Wittich CM, Burkle CM, Lanier WL. Medication errors: an overview for clinicians. Mayo Clin Proc. 2014;89(8):1116-1125.

31. Tam VC, Knowles SR, Cornish PL, Fine N, Marchesano R, Etchells EE. Frequency, type and clinical importance of medication history errors at admission to hospital: a systematic review. CMAJ. 2005;173(5):510-515.

32. Coleman EA, Smith JD, Raha D, Min SJ. Posthospital medication discrepancies: prevalence and contributing factors. Arch Intern Med. 2005; 165(16): 1842-1847.

33. Jack BW, Chetty VK, Anthony D, et al. A reengineered hospital discharge program to decrease rehospitalization: a randomized trial. Ann Int Med. 2009;150(3):178-187.

34. Cornish PL, Knowles SR, Marchesano R, et al. Unintended medication discrepancies at the time of hospital admission. Arch Intern Med. 2005;165(4):424-429.

35. Jones T, Jackson A. Assessment of medication errors that involved drug allergies at a university hospital. Pharmacotherapy. 2003;23(7):855-860.

36. Picard M, Begin P, Bouchard $\mathrm{H}$, et al. Treatment of patients with a history of penicillin allergy in a large tertiary-care academic hospital. J Allergy Clin Immunol Pract. 2013;1(3):252-257. 
37. Sastre J, Manso L, Sanchez-Garcia S, Fernandez-Nieto M. Medical and economic impact of misdiagnosis of drug hypersensitivity in hospitalized patients. J Allergy Clin Immunol Pract. 2012;129(2):566-567.

38. Barton L, Futtermenger J, Gaddi Y, et al. Simple prescribing errors and allergy documentation in medical hospital admissions in Australia and New Zealand. Clin Med. 2012;12(2):119-123.

39. Making Strides in Safety ${ }^{\circledR}$ program (C2007 American Medical Association. The physician's role in medication reconciliation Issues, strategies and safety principles. Available from: https://bcpsqc.ca/ documents/2012/09/AMA-The-physician $\%$ E2\%80\%99s-role-inMedication-Reconciliation.pdf. Accessed January 5, 2017.

40. Kern KA, Kalus JS, Bush C, Chen D, Szandzik EG, Haque NZ. Variations in pharmacy-based transition-of-care activities in the United States: a national survey. Am J Health Syst Pharm. 2014;71(8):648-656.

41. Kristeller J. Transition of care: pharmacist help needed. Hosp Pharm. 2014;49(3):215-216.

42. Sen S, Bowen JF, Ganetsky VS, et al. Pharmacists implementing transitions of care in inpatient, ambulatory and community practice settings. Pharm Pract (Granada). 2014;12(2):439.

43. Allende Bandres MA, Arenere Mendoza M, Gutierrez Nicolas F, Calleja Hernandez MA, Ruiz La Iglesia F. Pharmacist-led medication reconciliation to reduce discrepancies in transitions of care in Spain. Int J Clin Pharm. 2013;35(6):1083-1090.

44. Phatak A, Prusi R, Ward B, et al. Impact of pharmacist involvement in the transitional care of high-risk patients through medication reconciliation, medication education, and postdischarge call-backs (IPITCH Study). J Hosp Med. 2016;11(1):39-44.

45. Berkman ND, Sheridan SL, Donahue KE, Halpern DJ, Crotty K. Low health literacy and health outcomes: an updated systematic review. Ann Int Med. 2011;155(2):97-107.

46. Youmans SL, Schillinger D. Functional health literacy and medication use: the pharmacist's role. Ann Pharmacother. 2003;37(11):1726-1729.

47. Noureldin M, Plake KS, Morrow DG, Tu W, Wu J, Murray MD. Effect of health literacy on drug adherence in patients with heart failure. Pharmacotherapy. 2012;32(9):819-826.

48. Marvanova M, Roumie CL, Eden SK, Cawthon C, Schnipper JL, Kripalani S. Health literacy and medication understanding among hospitalized adults. J Hosp Med. 2011;6(9):488-493.

49. Mixon AS, Myers AP, Leak CL, et al. Characteristics associated with postdischarge medication errors. Mayo Clin Proc. 2014;89(8):1042-1051.

50. Hume K, Tomsik E. Enhancing patient education and medication reconciliation strategies to reduce readmission rates. Hosp Pharm. 2014;49(2): 112-114.

51. Balling L, Erstad BL, Weibel K. Impact of a transition-of-care pharmacist during hospital discharge. JAm Pharm Assoc. 2015;55(4):443-448.

52. Murphy EM, Oxencis CJ, Klauck JA, Meyer DA, Zimmerman JM. Medication reconciliation at an academic medical center: implementation of a comprehensive program from admission to discharge. Am J Health Syst Pharm. 2009;66(23):2126-2131.

53. Walker PC, Bernstein SJ, Jones JN, et al. Impact of a pharmacistfacilitated hospital discharge program: a quasi-experimental study. Arch Intern Med. 2009;169(21):2003-2010.

54. Cesarz JL, Steffenhagen AL, Svenson J, Hamedani AG. Emergency department discharge prescription interventions by emergency medicine pharmacists. Ann Emerg Med. 2013;61(2):209.e-214.e.

55. Ensing HT, Stuijt CC, van den Bemt BJ, et al. Identifying the optimal role for pharmacists in care transitions: a systematic review. J Manag Care Spec Pharm. 2015;21(8):614-636.
56. Gillespie U, Alassaad A, Henrohn D, et al. A comprehensive pharmacist intervention to reduce morbidity in patients 80 years or older: a randomized controlled trial. Arch Intern Med. 2009;169(9):894-900.

57. Rochester-Eyeguokan CD, Pincus KJ, Patel RS, Reitz SJ. The current landscape of transitions of care practice models: a scoping review. Pharmacotherapy. 2016;36(1):117-133.

58. Keller ME, Kelling SE, Cornelius DC, Oni HA, Bright DR. Enhancing practice efficiency and patient care by sharing electronic health records. Perspect Health Inf Manag. 2015;12:1b.

59. Williams H, Edwards A, Hibbert P, et al. Harms from discharge to primary care: mixed methods analysis of incident reports. $\mathrm{Br} J \mathrm{Gen}$ Pract. 2015;65(641):e829-e837.

60. Belda-Rustarazo S, Cantero-Hinojosa J, Salmeron-Garcia A, GonzalezGarcia L, Cabeza-Barrera J, Galvez J. Medication reconciliation at admission and discharge: an analysis of prevalence and associated risk factors. Int J Clin Pract. 2015;69(11):1268-1274.

61. Shiu JR, Fradette M, Padwal RS, et al. Medication discrepancies associated with a medication reconciliation program and clinical outcomes after hospital discharge. Pharmacotherapy. 2016;36(4):415-421.

62. Braund R, Coulter CV, Bodington AJ, et al. Drug related problems identified by community pharmacists on hospital discharge prescriptions in New Zealand. Int J Clin Pharm. 2014;36(3):498-502.

63. Maxwell K, Harrison J, Scahill S, Braund R. Identifying drug-related problems during transition between secondary care and primary care in New Zealand. Int J Clin Pharm. 2013;21(5):333-336.

64. Nazar H, Nazar Z, Portlock J, Todd A, Slight SP. A systematic review of the role of community pharmacies in improving the transition from secondary to primary care. Br J Clin Pharmacol. 2015;80(5): 936-948.

65. Farris KB, Carter BL, Xu Y, et al. Effect of a care transition intervention by pharmacists: an RCT. BMC Health Serv Res. 2014;14:406.

66. Luder HR, Frede SM, Kirby JA, et al. TransitionRx: impact of community pharmacy postdischarge medication therapy management on hospital readmission rate. $J$ Am Pharm Assoc. 2015;55(3):246-254.

67. Stone MC, Williams HC. Clinical pharmacists in general practice: value for patients and the practice of a new role. Br J Gen Pract. 2015;65(634): 262-263.

68. Bardet JD, Vo TH, Bedouch P, Allenet B. Physicians and community pharmacists collaboration in primary care: a review of specific models. Res Soc Adm Pharm. 2015;11(5):602-622.

69. Dey RM, de Vries MJ, Bosnic-Anticevich S. Collaboration in chronic care: unpacking the relationship of pharmacists and general medical practitioners in primary care. Int J Pharm Pract. 2011;19(1):21-29.

70. Freeman CW, Cottrell N, Kyle G, Williams ID, Nissen L. Pharmacists', general practitioners' and consumers' views on integrating pharmacists into general practice. J Pharm Pract Res. 2012;42(3):184-188.

71. Hatah E, Braund R, Duffull S, Tordoff J. General practitioners' views on pharmacists potential contribution to medication-related services in New Zealand. J Prim Health Care. 2013;5(3):223-233.

72. Tan EC, Stewart K, Elliott RA, George J. Integration of pharmacists into general practice clinics in Australia: the views of general practitioners and pharmacists. Int J Pharm Pract. 2013;22(1):28-37.

73. Tan EC, Stewart K, Elliott RA, George J. Pharmacist consultations in general practice clinics: the Pharmacists in Practice Study (PIPS). Res Social Adm Pharm. 2014;10(4):623-632.

74. Brown MT, Bussell J, Dutta S, Davis K, Strong S, Mathew S. Medication adherence: truth and consequences. Am J Med Sci. 2016;351(4): 387-399. 
Integrated Pharmacy Research and Practice is an international, peer-reviewed, open access, online journal, publishing original research, reports, reviews and commentaries on all areas of academic and professional pharmacy practice. This journal aims to represent the academic output of pharmacists and pharmacy practice with particular focus on integrated care. All papers are carefully peer reviewed to ensure the highest standards as well as ensuring that we are informing and stimulating pharmaceutical professionals. The manuscript management system is completely online and includes a very quick and fair peer-review system, which is all easy to use. Visit http://www.dovepress.com/ testimonials.php to read real quotes from published authors.

Submit your manuscript here: http://www.dovepress.com/integrated-pharmacy-research-and-practice-journal 